\title{
Regression equations for circular CFST columns carrying capacity evaluation
}

\author{
Glib Vatulia ${ }^{1 *}$, Maryna Rezunenko ${ }^{1}$, Yevhen Orel $^{1}$ and Dmytro Petrenko ${ }^{1}$ \\ ${ }^{1}$ Ukrainian State University of Railway Transport, Structural Mechanics and Hydraulics Department, \\ Feuerbach sq. 7, 61050 Kharkiv, Ukraine
}

\begin{abstract}
Within the last decades, a considerable amount of experimental studies have been carried out by numerous researchers across the world with the purpose to study the carrying capacity of concrete-filled steel tubular (CFST) columns and evaluation of their stressed-strained state. The array of the obtained results have allowed designing a mathematical model to determine the maximum carrying capacity value of such constructions using the methods of mathematical statistics. The authors obtained three types of regression equations for short and long circular CFST columns with different geometrical and physical properties under axial compression. Statistical quality of the obtained models was verified by both regression equation quality in general and statistical significance of the equation parameters. The comparison of the obtained carrying capacity values with the results calculated by Eurocode 4 and AIJ methodologies allows making a conclusion on the sufficient calculation accuracy of the designed mathematical models.
\end{abstract}

\section{Introduction}

Since the steel concrete columns have been commonly used in the civil engineering, the issues of research of their carrying capacity and evaluation of the stressed-strained state still remain very important today. The extensive experimental data set on carrying capacity of the columns under various loading conditions assembled within the latest decades by the researchers across the world has enabled to study the behaviour of the columns using the techniques of mathematical statistics [1-6].

The authors of this research have built mathematical models to evaluate the maximum carrying capacity of circular CFST columns under axial compression. One of the most widely used statistical techniques was used for this purpose, namely, regression analysis [7].

Initially, two models were supposed to be built for circular CFST short $(L / D<4)$ and long $(L / D \geq 4)$ columns, where $L, D$ - length and outer diameter of the column, respectively.

\footnotetext{
*Corresponding author: glebvatulya@gmail.com
} 
However, analysis of the obtained results showed that in case of the long columns it would be preferable to consider separately the samples with the casing thickness $t<2.5$ $\mathrm{mm}$ and those with the thickness $t \geq 2.5 \mathrm{~mm}$.

\section{Regression equation}

\subsection{CFST long thin-walled columns}

In the first case, thin-wall steel concrete circular columns with $t<2.5 \mathrm{~mm}$, ratio $L / D \geq 4$, column diameter varying within $76 \leq D \leq 210 \mathrm{~mm}$, length $500 \leq L \leq 2750 \mathrm{~mm}$, yield strength of steel $186 \leq \sigma_{y} \leq 490 \mathrm{MPa}$, modulus of elasticity of steel $1.68 \cdot 10^{5} \leq E_{s} \leq$ $2.17 \cdot 10^{5} \mathrm{MPa}$, prism strength of concrete $10 \leq f_{\text {c,prizm }} \leq 50 \mathrm{MPa}$, modulus of elasticity of concrete $2.0 \cdot 10^{4} \leq E_{c} \leq 3.6 \cdot 10^{4} \mathrm{MPa}$ were considered. In the series of $n=40$ observations, a factor regression model was obtained as follows:

$$
\begin{gathered}
\bar{N}=a_{0}+a_{1} \frac{D^{2} E_{s}}{\sigma_{y}}+a_{2} \frac{D L}{t}+a_{3} D f_{c, \text { prizm }}+a_{4}\left(\frac{D}{t}\right)^{2} \frac{1}{E_{c}}= \\
=163.3128+0.0309 \frac{D^{2} E_{s}}{\sigma_{y}}-0.0021 \frac{D L}{t}+0.0526 D f_{c, p r i z m}+0.381\left(\frac{D}{t}\right)^{2} \frac{1}{E_{c}} .
\end{gathered}
$$

\subsection{CFST long thick-walled columns}

In the second case, circular CFST columns with the casing thickness at least $2.5 \mathrm{~mm}$, ratio $L / D \geq 4$, column diameter varying within $88 \leq D \leq 267 \mathrm{~mm}$, length $485 \leq L \leq 4956 \mathrm{~mm}$, yield strength of steel $200 \leq \sigma_{y} \leq 490 \mathrm{MPa}$, modulus of elasticity of steel $1.68 \cdot 10^{5} \leq E_{s} \leq$ $2.17 \cdot 10^{5} \mathrm{MPa}$, prism strength of concrete $18.2 \leq f_{c \text {,prizm }} \leq 50 \mathrm{MPa}$, modulus of elasticity of concrete $2.0 \cdot 10^{4} \leq E_{c} \leq 3.6 \cdot 10^{4} \mathrm{MPa}$ were considered. A regression model built on the basis of $n=224$ observations is written as:

$$
\begin{gathered}
\bar{N}=a_{0}+a_{1} D E_{s}+a_{2}(D-2 t) L \sigma_{y}+a_{3} D^{2} f_{c, p r i z m}+a_{4} \frac{(D-2 t)^{2} t}{E_{c}}+a_{5} \frac{(D-2 t) t}{\sigma_{y}}= \\
=213.5814+0.0291 D E_{s}-4.5 \cdot 10^{-6}(D-2 t) L \sigma_{y}+0.0007 D^{2} f_{c, p r i z m}+ \\
+0.2322 \frac{(D-2 t)^{2} t}{E_{c}}-1518.73 \frac{(D-2 t) t}{\sigma_{y}} .
\end{gathered}
$$

\subsection{CFST short columns}

In the third case, circular CFST short columns with ratio $L / D<4$, column diameter varying within $86 \leq D \leq 820 \mathrm{~mm}$, length $200 \leq L \leq 2460 \mathrm{~mm}$, yield strength of steel $226 \leq \sigma_{y} \leq$ $490 \mathrm{MPa}$, modulus of elasticity of steel $1.68 \cdot 10^{5} \leq E_{s} \leq 2.17 \cdot 10^{5} \mathrm{MPa}$, prism strength of concrete $18 \leq f_{c, \text { prizm }} \leq 50 \mathrm{MPa}$, modulus of elasticity of concrete $2.0 \cdot 10^{4} \leq E_{c} \leq 3.6 \cdot 10^{4}$ $\mathrm{MPa}$ were considered. Based on the study of the results of 156 experiments, the regression equation is written as:

$$
\begin{aligned}
& \bar{N}=a_{0}+a_{1} D t+a_{2} D^{2} f_{c, \text { prizm }}+a_{3} L \sigma_{y}^{2}+a_{4} t^{2} \sigma_{y} L=-81,3206+ \\
& +0.9297 D t+7.53 \cdot 10^{-4} D^{2} f_{c, p r i z m}+7.75 \cdot 10^{-6} L \sigma_{y}^{2}+8.94 \cdot 10^{-8} t^{2} \sigma_{y} L .
\end{aligned}
$$




\section{Confidence intervals and comparative analysis}

Confidence intervals for regression equation parameters with probability $P=0.95$ are shown in Table 1.

Table 1. Confidence intervals.

\begin{tabular}{|c|c|c|}
\hline Model 1 & Model 2 & Model 3 \\
\hline $108.13 \leq a_{0} \leq 218.5 ;$ & $119.173 \leq a_{0} \leq 307.99 ;$ & $-134.305 \leq a_{0} \leq-28.3359 ;$ \\
$0.029 \leq a_{1} \leq 0.033 ;$ & $0.0219 \leq a_{1} \leq 0.0364 ;$ & $-0.848 \leq a_{1} \leq-1.012 ;$ \\
$-0.0025 \leq a_{2} \leq-0.0017 ;$ & $-4.8 \times 10^{-6} \leq a_{2} \leq-4.2 \cdot 10^{-6} ;$ & $7.39 \cdot 10^{-4} \leq a_{2} \leq 7.67 \cdot 10^{-4} ;$ \\
$0.039 \leq a_{3} \leq 0.067 ;$ & $6.5 \times 10^{-4} \leq a_{3} \leq 7.8 \cdot 10^{-4} ;$ & $6.75 \cdot 10^{-6} \leq a_{3} \leq 8.74 \cdot 10^{-6} ;$ \\
$0.113 \leq a_{4} \leq 0.649$ & $0.231 \leq a_{4} \leq 0.2506 ;$ & $6.66 \cdot 10^{-8} \leq a_{4} \leq 1.12 \cdot 10^{-7}$ \\
\hline
\end{tabular}

Comparative analysis of experimental and theoretical values of the carrying capacity of circular CFST columns for all the above regression models are shown in Fig. 1-3.

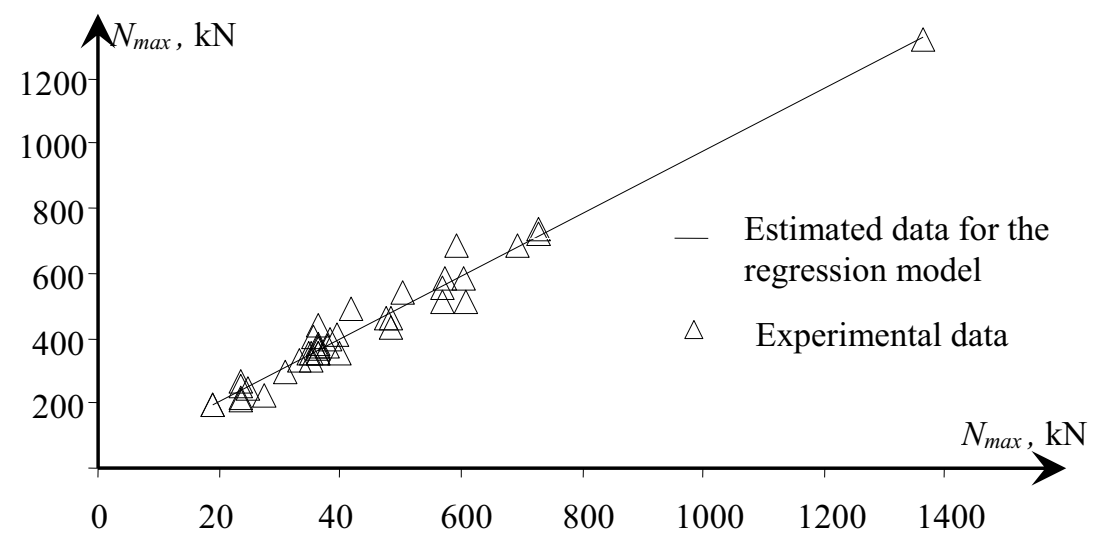

Fig. 1. Carrying capacity of concrete-filled steel tubular columns $(t<2.5 \mathrm{~mm}, L / D \geq 4)$. 


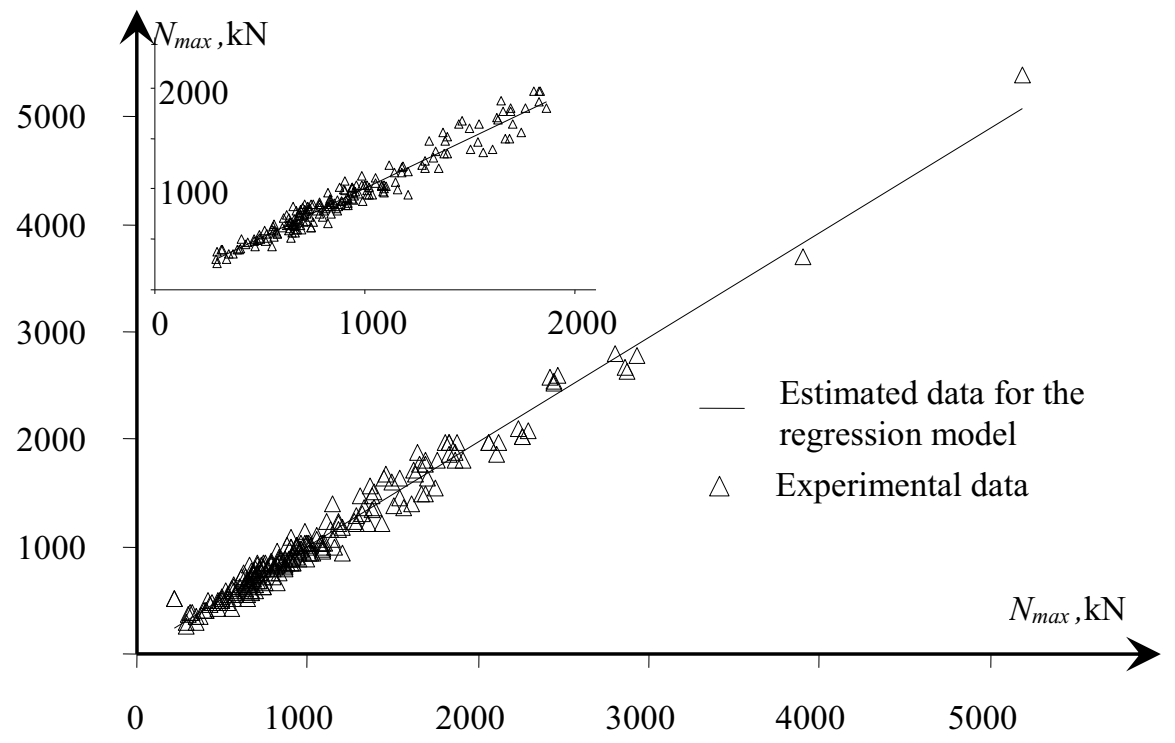

Fig. 2. Carrying capacity of concrete-filled steel tubular columns ( $t \geq 2.5 \mathrm{~mm}, L / D \geq 4)$.

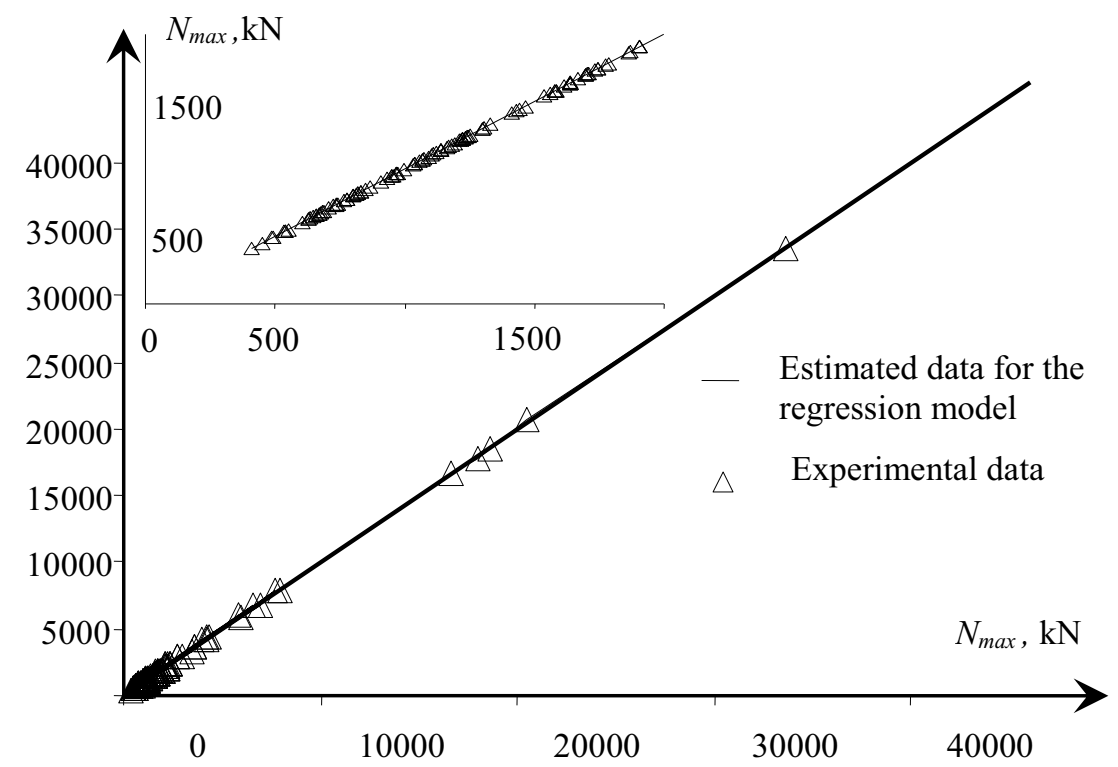

Fig. 3. Carrying capacity of concrete-filled steel tubular columns $(L / D<4)$.

Dependences of absolute error $\Delta N_{\text {max }}=\left|\frac{N_{\text {theor }}}{N_{\text {exp }}}\right|$ on geometrical parameters of the columns and correlation thereof are shown in Fig. $4 \div 6$ for models $(1) \div(3)$, respectively. 


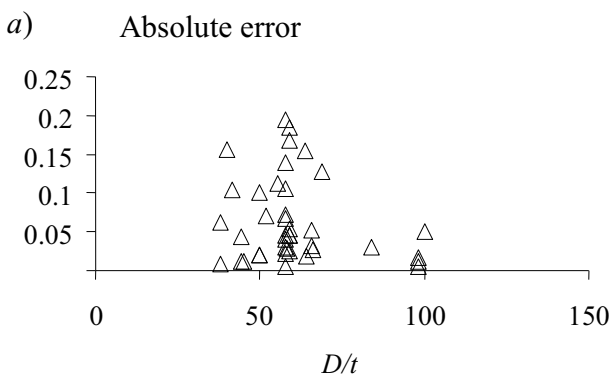

c) Absolute error

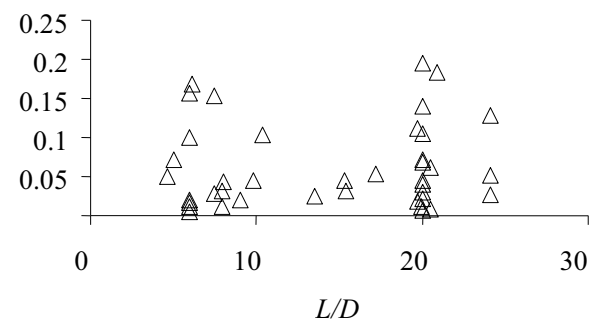

b) Absolute error

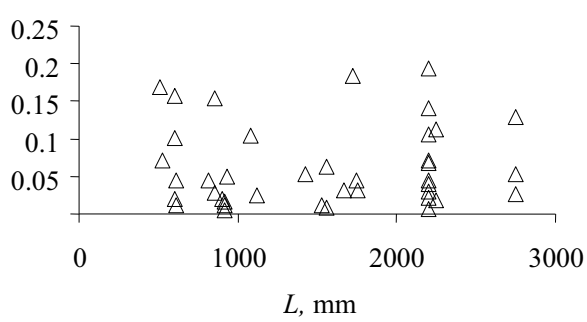

d) Absolute error

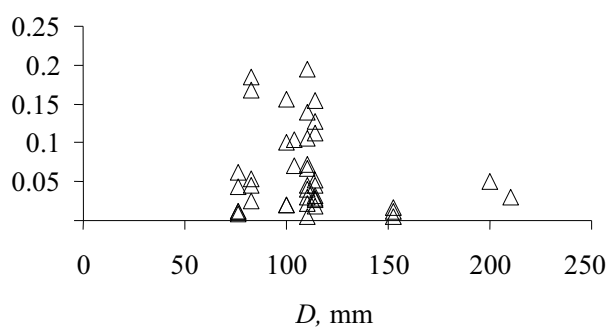

Fig. 4. Dependences of absolute error of the regression model 1: $a-$ on $D / t$ value; $b$ - on the length of the column $L ; c-$ on $L / D$ value, $d$ - on external diameter $D$.
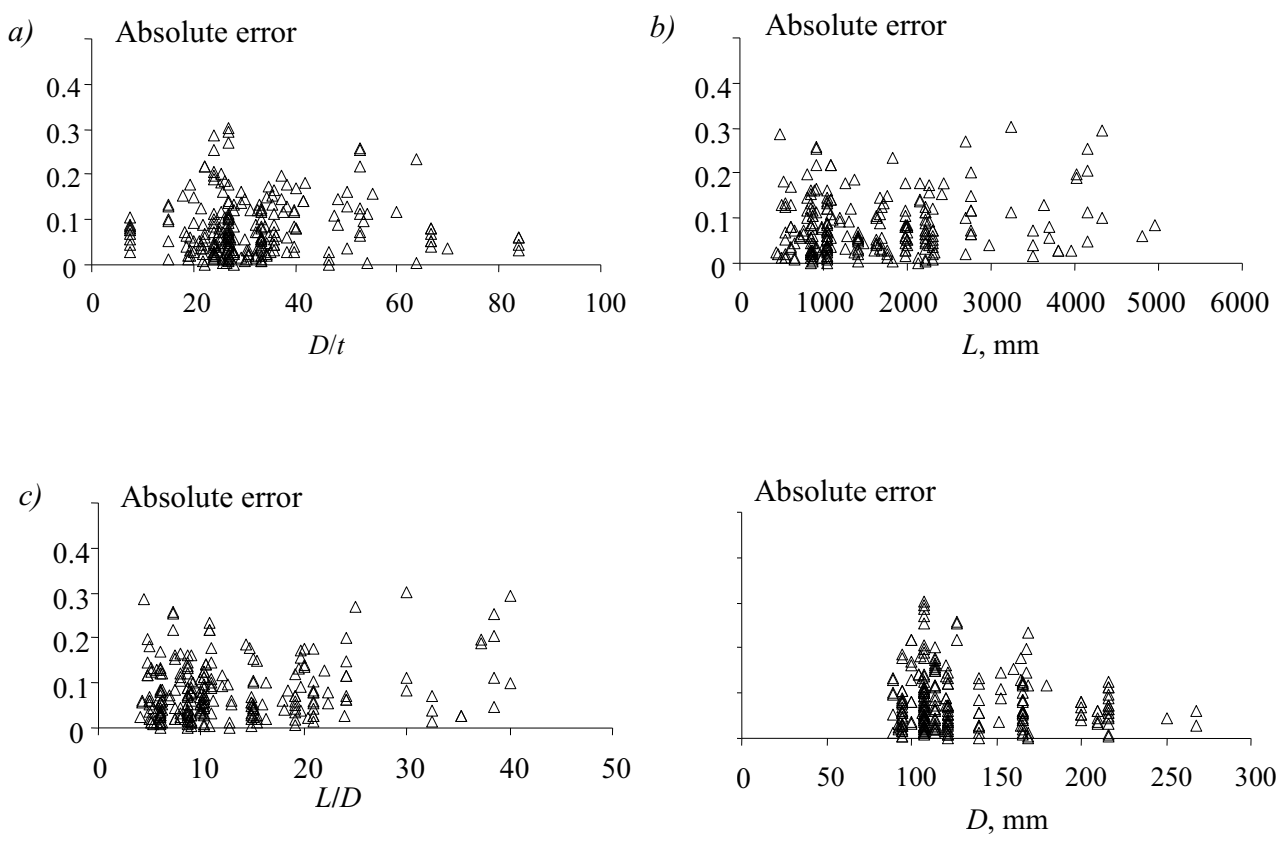

Fig. 5. Dependences of absolute error of the regression model 2:

$a-$ on $D / t$ value; $b-$ on the length of the column $L ; c-$ on $L / D$ value $d$ - on external diameter $D$. 
a)

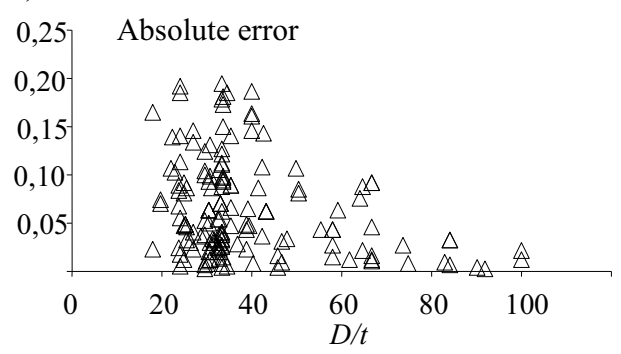

c)

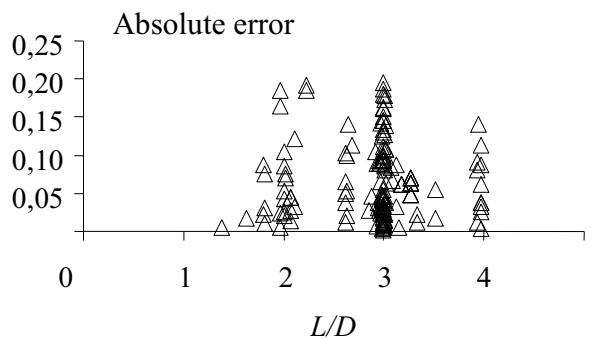

b)

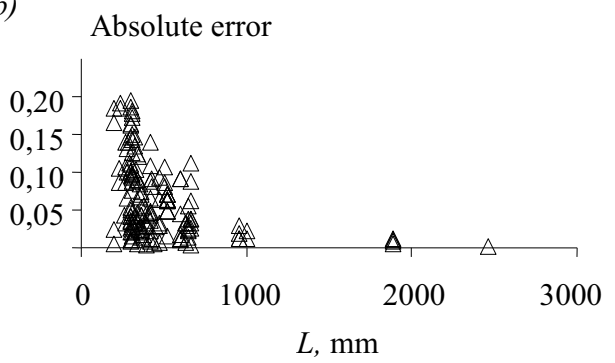

d)

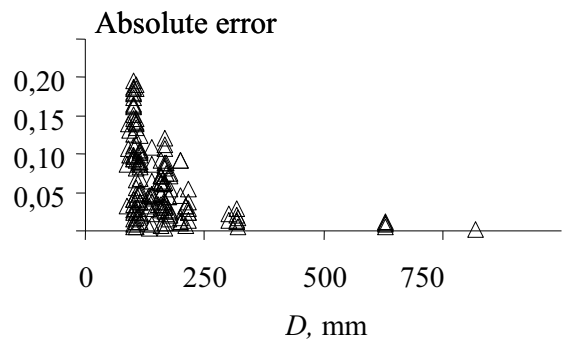

Fig. 6. Dependences of absolute error of the regression model 3:

$a-$ on $D / t$ value; $b-$ on the length of the column $L ; c-$ on $L / D$ value $d$ - on external diameter $D$.

In Table 2, quality parameters of the built models, such as coefficient of determination $R^{2}$ and mean approximation error are given

$$
\Delta=\frac{1}{n} \sum_{i=1}^{n} \frac{\left|N_{\text {exp }}-N_{\text {theor }}\right|}{N_{\text {exp }}} 100 \% .
$$

Table 2. Quality parameters of the models.

\begin{tabular}{|c|c|c|c|}
\hline & Model 1 & Model 2 & Model 3 \\
\hline Coefficient of determination $R^{2}$ & 0.989 & 0.988 & 0.99 \\
\hline Mean approximation error & $6.30 \%$ & $7.68 \%$ & $6.41 \%$ \\
\hline
\end{tabular}

Study of the remainder $\left(N_{\text {exp }}-N_{\text {theor }}\right)$ for models $(1) \div(3)$ shows that they are normally distributed with zero probabilistic expectation and lie within the interval $[-3 S ; 3 S]$, where $S$ corrected mean quadratic deviation which is $47.94(t<2.5 \mathrm{~mm}, L / D \geq 4), 97.55(t \geq 2.5 \mathrm{~mm}$, $L / D \geq 4), 104.74(L / D<4)$. Moreover, in all cases, about $71 \%$ remainder are in the interval $[-S ; S], 98 \%, 94 \%$ and $96 \%$, respectively - in the interval $[-2 S ; 2 S]$.

In general, the statistical significance of the regression equations is verified with the Fisher criterion, while the statistical significance of the equation parameters is verified with the Student criterion.

The performed mathematical analysis of the obtained models, as well as comparison of the results with the carrying capacity value of the circular CFST columns calculated using the 
methods of Eurocode 4 [8] and Architecture Institute of Japan (AIJ) [9] allow to make a conclusion that the degree of confidence of the regression equations $(1) \div(3)$ is sufficiently high.

\section{References}

1. E.D. Chikhladze, G.L. Vatulia, Y.P. Kitov, Basis for calculation and design of composite and steel-concrete constructions, Transport of Ukraine, 104 (2006)

2. G.L. Vatulia, Rozrakhunok ta proektuvannya stalebetonnykh ta kombinovanykh konstruktsiy. Kharkiv, 409 (2015)

3. T. Yamamoto, J. Struct. Constr. Eng., Transactions of AIJ 561, 237-244 (2002)

4. A.L. Krishan, A.S. Melnitchuk, News of KSUAE, Kaza, 3 (29), 6-50 (2014)

5. L.I. Storozhenko, D.A. Ermolenko, O.I. Lapenko, Tube confined concrete, ASMI, Poltava, 306 (2010)

6. I. Nishiyama, S. Morino, K. Sakino, H. Nakahara, Summary of Research on ConcreteFilled Structural Steel Tube Column System Carried Out Under The US-JAPAN Cooperative Research Program on Composite and Hybrid Structures, Tokyo, 176 (2002)

7. I. Vuchkov, Prikladnoy lineynyiy regressionnyiy analiz. Finance and Statistics, 239 (1987)

8. Design of composite steel and concrete structures - Part 1-1: General Rules and Rules for Bridges. EN 1994-1: 2001. Eurocode 4, Brussels, 96 (2006)

9. Recommendations for design and construction of concrete filled steel tubular structures, Architectural Institute of Japan (AIJ), Tokyo, 333 (1997) 